Check for updates

Cite this: Mater. Adv., 2021, 2, 2382

Received 22nd November 2020, Accepted 1st March 2021

DOI: 10.1039/d0ma00912a

rsc.li/materials-advances

\title{
High carrier mobility and ultralow thermal conductivity in the synthetic layered superlattice $\mathrm{Sn}_{4} \mathrm{Bi}_{10} \mathrm{Se}_{19} \dagger$
}

\author{
Ruiming Lu, $\ddagger^{\mathrm{a}}$ Alan Olvera, $\ddagger^{\mathrm{a}}$ Trevor P. Bailey, (D) ${ }^{\mathrm{b}}$ Jiefei Fu, ${ }^{\mathrm{c}}$ Xianli Su, (D) ${ }^{\mathrm{c}}$ \\ Igor Veremchuk, ${ }^{\mathrm{d}}$ Zhixiong Yin, ${ }^{\mathrm{a}}$ Brandon Buchanan, ${ }^{\mathrm{a}}$ Ctirad Uher, \\ Xinfeng Tang, (D) ${ }^{c}$ Yuri Grin ${ }^{d}$ and Pierre F. P. Poudeu (D) $\star^{a}$
}

\begin{abstract}
The integration within the same crystal lattice of two or more structurally and chemically distinct building units enables the design of complex materials featuring the coexistence of dissimilar functionalities. Here we report the successful synthesis of single-phase polycrystalline powder of $\mathrm{Sn}_{4} \mathrm{Bi}_{10} \mathrm{Se}_{19}$, a ternary selenide featuring atomic-scale integration of $\mathrm{SnSe}$-type and $\mathrm{Bi}_{2} \mathrm{Se}_{3}$-type building blocks into a large monoclinic unit cell. We found that the complex layered atomic structure along with the large size of the building blocks severely impede the crystallization of an ordered phase. Consequently, the electronic and thermal transport properties of $\mathrm{Sn}_{4} \mathrm{Bi}_{10} \mathrm{Se}_{19}$ are strongly influenced by the degree of crystallinity and atomic ordering within the crystal lattice. At temperatures below $300 \mathrm{~K}$, the well-crystallized $\mathrm{Sn}_{4} \mathrm{Bi}_{10} \mathrm{Se}_{19}$ sample displays higher carrier density, carrier mobility, and electrical conductivity compared to the poorly crystallized sample, while both samples show similar electronic properties at high temperatures. Astonishingly, the crystalline sample exhibits up to $30 \%$ lower thermal conductivity at $535 \mathrm{~K}$ compared to the poorly crystallized sample. This suggests a more efficient phonon scattering at the ordered atomic-scale interfaces between the building blocks in the crystalline sample, owing to bond inhomogeneity and anisotropy, whereas the random orientation of building blocks in the poorly crystallized sample inhibits such effect.
\end{abstract}

\section{Introduction}

Energy conversion from renewable and sustainable sources is necessary to tackle the perpetual growth of the global energy demand. Over the past decades, thermoelectric research has led to the development of several concepts and strategies, such as multicomponent nanostructuring, ${ }^{1}$ phonon-glass electroniccrystals (PGEC), ${ }^{2}$ resonant level impurities, ${ }^{3}$ and electron energyfiltering, ${ }^{4-6}$ which have enabled the discovery and optimization of a wide range of materials with high figure of merit, $Z T=S^{2} \sigma T / \kappa_{\text {total }}$

\footnotetext{
${ }^{a}$ Laboratory for Emerging Energy and Electronic Materials, Department of Materials Science and Engineering, University of Michigan, Ann Arbor, Michigan 48109, USA. E-mail: ppoudeup@umich.edu; Fax: +1-734-763-4788

${ }^{b}$ Department of Physics, University of Michigan, Ann Arbor, Michigan 48109, USA

${ }^{c}$ State Key Laboratory of Advanced Technology for Materials Synthesis and Processing, Wuhan University of Technology, Wuhan, Hubei 430070, China

${ }^{d}$ Max-Planck-Institut für Chemische Physik Fester Stoffe, Nöthnitzer Straße 40, 01187 Dresden, Germany

$\dagger$ Electronic supplementary information (ESI) available: Experimental details, Tables S1-S4 and Fig. S1-S5, X-ray crystallographic data, in CIF format, for the single crystal structure refinements of $\mathrm{Sn}_{4} \mathrm{Bi}_{10} \mathrm{Se}_{19}$ (CCDC_1942969) at $300 \mathrm{~K}$. For ESI and crystallographic data in CIF or other electronic format see DOI: 10.1039/ d0ma00912a

\# Contributed equally.
}

( $S$ is the Seebeck coefficient, $\sigma$ is electrical conductivity, $T$ is absolute temperature, and $\kappa_{\text {total }}$ is total thermal conductivity). ${ }^{7-12}$ However, general and widespread sustainable applications ${ }^{13,14}$ of thermoelectric technology require the development of low-cost, high-performance materials from abundant and environmentally friendly elements. Therefore, recent trends in thermoelectric research have focused on the development of binary, ternary and quaternary metal chalcogenides. ${ }^{15-17}$ Their structural diversity and compositional flexibility enable functional properties (thermal, electronic, etc.) engineering through manipulation of the stoichiometry, chemical composition, and distribution of metal atoms in the chalcogenide crystal lattice. For instance, high $Z T$ values were recently reported for chemically simple binary compounds, such as SnSe $(Z T \sim 2.6 \text { at } 923 \mathrm{~K})^{17,18}$ and $\mathrm{Cu}_{2} \mathrm{Se}(Z T \sim 1.5$ at $1000 \mathrm{~K}),{ }^{16,19-24}$ demonstrating promising materials for high temperature power generation applications. The integration of $\mathrm{Cu}_{2} \mathrm{Se}$ and SnSe phases into $\left(\mathrm{Cu}_{2} \mathrm{Se}\right)_{1-x}(\mathrm{SnSe})_{x}$ bulk composites led to $Z T$ values as high as 1.4 at $825 \mathrm{~K}^{19}$ However, less attention is allocated to the discovery and optimization of metal chalcogenides for mid-temperature range (300 $\mathrm{K}$ to $700 \mathrm{~K}$ ) and cooling applications. The few notable examples are $\mathrm{CsBi}_{4} \mathrm{Te}_{6}(Z T \sim 0.8$ at $225 \mathrm{~K}),{ }^{25}$ and various compositions of the solid solution series $\mathrm{Bi}_{2-x} \mathrm{Sb}_{x} \mathrm{Te}_{3-y} \mathrm{Se}_{y}{ }^{26,27}$ In addition to the 
optimization of the thermoelectric properties of known binary and ternary compounds, significant effort is also invested in the search for new metal chalcogenides with increasing compositional, structural and bonding ${ }^{28}$ complexity, with the goal of creating multifaceted electronic band structures concurrent with ultralow thermal conductivity. ${ }^{15}$ Along this line, the concept of phase homology is gaining considerable attraction as an elegant approach for the prediction and synthesis of novel promising thermoelectric materials. ${ }^{29-31}$ The compositional and structural flexibility of homologous structures offer the possibility of engineering the electronic band structure, the inhomogeneity of chemical bonding, which influences the phonon vibration modes of various members of the homologous series, in order to achieve compounds with high thermoelectric performance, i.e. high electrical conductivity $(\sigma)$ and Seebeck coefficient $(S)$ and ultralow thermal conductivity $(K)$. Several naturally occurring and synthetic mixed-metal chalcogenides homologous series have been reported. These include, $\mathrm{A}_{m}\left[\mathrm{M}_{1+l} \mathrm{Se}_{2+l}\right]_{2 m}\left[\mathrm{M}_{2 l+n} \mathrm{Se}_{2+3 l+n}\right](\mathrm{A}=\mathrm{K}, \mathrm{Rb}$, Cs and $\mathrm{M}=\mathrm{Sn}, \mathrm{Pb}$ ) where $l, m$, and $n$ represent the size of various structural building units; ${ }^{32,33} \quad[\mathrm{BiQX}]_{2}\left[\mathrm{Ag}_{x} \mathrm{Bi}_{1-x} \mathrm{Q}_{2-2 x} \mathrm{X}_{2 x-1}\right]_{N+1}$ $(\mathrm{Q}=\mathrm{S}$, Se; $\mathrm{X}=\mathrm{Cl}, \mathrm{Br} ; 1 / 2 \leq x \leq 1) ;{ }^{31}$ the pavonite, $\mathrm{M}_{N+1} \mathrm{Bi}_{2} \mathrm{~S}_{N+5}$ $(\mathrm{M}=\mathrm{Ag} / \mathrm{Bi}$ or $\mathrm{Cu} / \mathrm{Bi} ; N \geq 2) ;{ }^{34}$ and the lillianite, $\mathrm{Pb}_{N-1-2 x} \mathrm{Bi}_{2+x}$ $\mathrm{Ag}_{x} \mathrm{~S}_{N+2},{ }^{35}$ and the $\mathrm{Pb}_{N-1} \mathrm{Bi}_{2} \mathrm{Se}_{N+2}{ }^{36}$ homologous series, where $N=(N 1+N 2) / 2$ representing the average of the number of edgesharing octahedra running across the central diagonal of the two NaCl-type building units forming the crystal structure. Among these homologous families of complex mixed-metal chalcogenides, phases belonging to the pseudo binary $\mathrm{PbSe}-\mathrm{Bi}_{2} \mathrm{Se}_{3}$ phase diagram, such as ternary compounds consisting of varying ratios of $(\mathrm{PbSe})_{m}\left(\mathrm{Bi}_{2} \mathrm{Se}_{3}\right)_{n}$ layers ${ }^{37-41}$ and $\mathrm{Pb}_{N-1} \mathrm{Bi}_{2} \mathrm{Se}_{N+2},{ }^{36}$ have been attracting considerable attention for thermoelectric application due to their moderately lower electrical resistivity compared to their sulfide analogues. For example, moderate electronic properties and low thermal conductivities have been reported for members of the $\mathrm{Pb}_{N-1} \mathrm{Bi}_{2} \mathrm{Se}_{N+2}$ series, such as $\mathrm{Pb}_{5} \mathrm{Bi}_{6} \mathrm{Se}_{14},{ }^{42} \mathrm{~Pb}_{7} \mathrm{Bi}_{4} \mathrm{Se}_{13},{ }^{36}$ and the recently discovered narrow band gap degenerate n-type semiconductor, $\mathrm{Pb}_{6} \mathrm{Bi}_{2} \mathrm{Se}_{9}$, with low thermal conductivity $\left(\sim 1.1 \mathrm{~W} \mathrm{~m}^{-1} \mathrm{~K}^{-1}\right.$ at $300 \mathrm{~K})$ and a moderate figure of merit, $Z T \sim 0.25$ at $650 \mathrm{~K}^{43}$

Following the example of the $\left(\mathrm{PbSe}_{w}\left(\mathrm{Bi}_{2} \mathrm{Se}_{3}\right)_{t}\right.$ family mentioned above, we have recently embarked on the search for new Earthabundant ternary thermoelectric materials for mid-temperature range applications within the $(\mathrm{SnSe})_{w}\left(\mathrm{Bi}_{2} \mathrm{Se}_{3}\right)_{t}$ system. It is anticipated that in such a system the integration at the atomic scale of structural features from $\mathrm{SnSe}$ and $\mathrm{Bi}_{2} \mathrm{Se}_{3}$ phases, which are promising thermoelectric materials suitable for applications at high temperatures and below room temperature, respectively, can create compounds suitable for mid-range ( $300 \mathrm{~K}$ to $700 \mathrm{~K}$ ) power generation application. Early investigations in the $\mathrm{SnSe}-\mathrm{Bi}_{2} \mathrm{Se}_{3}$ phase space led to the discovery of several ternary compounds, which are structurally related to the lillianite homologous series with general formula $\mathrm{M}_{N-1} \mathrm{Bi}_{2} \mathrm{Se}_{N+2},(\mathrm{M}=\mathrm{Sn}$ or $(\mathrm{Sn} / \mathrm{Bi} / \square)$ where $\square$ = vacant site). These include, the $\mathrm{Sn}_{2} \mathrm{Bi}_{2} \mathrm{Se}_{5}(N=3) ;{ }^{44} \mathrm{Sn}_{4} \mathrm{Bi}_{2} \mathrm{Se}_{7}$ $(N=5) ;{ }^{44} \mathrm{Sn}_{2.22} \mathrm{Bi}_{2.52} \mathrm{Se}_{6} \cong\left(\square_{0.3} \mathrm{Sn}_{2.2} \mathrm{Bi}_{0.5}\right) \mathrm{Bi}_{2} \mathrm{Se}_{6} \quad(N=4) ;{ }^{45}$ $\left(\mathrm{Sn}_{3} \mathrm{Bi}_{2} \mathrm{Se}_{6}(N=4) ;{ }^{46} \mathrm{SnBi}_{4} \mathrm{Se}_{7} \cong\left(\square \mathrm{SnBi}_{2}\right) \mathrm{Bi}_{2} \mathrm{Se}_{7}(N=5) ;^{44}\right.$ $\mathrm{Sn}_{3.6} \mathrm{Bi}_{3.6} \mathrm{Se}_{9} \cong\left(\square_{1.8} \mathrm{Sn}_{3.6} \mathrm{Bi}_{1.6}\right) \mathrm{Bi}_{2} \mathrm{Se}_{9}(N=7){ }^{45} \mathrm{Sn}_{6} \mathrm{Bi}_{2} \mathrm{Se}_{9}(N=7) ;{ }^{46}$ $\mathrm{Sn}_{9.52} \mathrm{Bi}_{10.96} \mathrm{Se}_{26} \cong\left(\square_{1.7} \mathrm{Sn}_{4.8} \mathrm{Bi}_{3.5}\right) \mathrm{Bi}_{2} \mathrm{Se}_{13} \quad(N=11) ;{ }^{45}$ and
$\mathrm{Sn}_{11.49} \mathrm{Bi}_{12.39} \mathrm{Se}_{30} \cong\left(\square_{2.1} \mathrm{Sn}_{5.7} \mathrm{Bi}_{4.2}\right) \mathrm{Bi}_{2} \mathrm{Se}_{15}(N=13)^{45}$ compounds, which are lillianite phases containing various degrees of structural vacancies. However, these compounds do not contain structural features of the $\mathrm{SnSe}$ and/or $\mathrm{Bi}_{2} \mathrm{Se}_{3}$ phases, since the lillianite structure is characterized by two alternating NaCl-type slabs (with thickness $N 1$ and N2).

Here, we report on the synthesis, crystal structure and thermoelectric properties of $\mathrm{Sn}_{4} \mathrm{Bi}_{10} \mathrm{Se}_{19}$, the first vacancy-free example of $(\mathrm{SnSe})_{w}\left(\mathrm{Bi}_{2} \mathrm{Se}_{3}\right)_{t}$ phases with crystal structure consisting of chemically integrated SnSe-type and $\mathrm{Bi}_{2} \mathrm{Se}_{3}$-type building units. We found that the $\mathrm{Sn}_{4} \mathrm{Bi}_{10} \mathrm{Se}_{19}$ phase integrates the high-carrier mobility observed in $\mathrm{Bi}_{2} \mathrm{Se}_{3}$ crystals with the low thermal conductivity of SnSe, which makes it an example of a synthetically accessible phonon-glass-electron-crystal (PGEC) superlattice with promising thermoelectric properties.

\section{Results and discussion}

\section{Crystal structure}

$\mathrm{Sn}_{4} \mathrm{Bi}_{10} \mathrm{Se}_{19}$ crystallizes in the monoclinic space group $C 2 / m$ (\#12) with lattice parameters $a=28.152(6) \AA, b=4.1567(8) \AA$, $c=21.242(4) \AA, \beta=131(3)^{\circ}$ and adopts a complex crystal structure, which consists of three distinct building blocks denoted A, B and C (Fig. 1).

The building unit $\mathrm{A}\left(\mathrm{Bi}_{2} \mathrm{Se}_{3}\right.$-type) is a cutout from the $\mathrm{Bi}_{2} \mathrm{Se}_{3}$ structure and contains two rows of four crystallographically independent metal positions (M1, M2, M4 and M5) that are octahedrally coordinated by Se atoms with various degrees of distortions (Table S1 and Fig. S1, ESI $\dagger$ ). The building unit B (SnSe-type) can be extracted from the structure of SnSe and consists of two rows of two crystallographically independent metal positions (M3 and M6) in distorted octahedral geometries. The building unit $\mathrm{C}$ is a single chain of face-sharing bicapped trigonal prisms $[1+2+2+1+2]$ around the crystallographically independent metal position, M7. All metal positions in the $\mathrm{Sn}_{4} \mathrm{Bi}_{10} \mathrm{Se}_{19}$ structure feature $\mathrm{Bi} / \mathrm{Sn}$ mixed occupancy in various ratios. Details on distortion and $\mathrm{M}-\mathrm{Se}$ bond distances are found in Table S1 (ESI $\dagger$ ). In the three dimensional (3D) structure, the $\mathrm{Bi}_{2} \mathrm{Se}_{3}$-type (A) building blocks are interconnected along [100] through edge-sharing $\mathrm{M}(4) \mathrm{Se}_{6}$ octahedra to form a two dimensional (2D) sheet parallel to the (001) plane. Adjacent $\mathrm{Bi}_{2} \mathrm{Se}_{3}$-type sheets are separated along [001] by discrete SnSetype (B) building blocks that are terminated at both ends by the building unit $\mathrm{C}$. This atomic scale assembly of the building blocks leads to a structure that resembles a synthetic layered superlattice formed by a $2 \mathrm{D} \mathrm{Bi}_{2} \mathrm{Se}_{3}$-layer and a $2 \mathrm{D}$ SnSe-layer that are stitched together alternatively along [001]. Similar complex structural organization was also observed in compounds such as $\mathrm{Cu}_{2} \mathrm{~Pb}_{6} \mathrm{Bi}_{8} \mathrm{~S}_{19},{ }^{47} \mathrm{~K}_{0.66} \mathrm{Sn}_{4.82} \mathrm{Bi}_{11.18} \mathrm{Se}_{22}{ }^{48}$ and $\mathrm{Sn}_{4.11} \mathrm{Bi}_{22.60} \mathrm{Se}_{38}{ }^{49}$ which is the defect analog of $\mathrm{Sn}_{4} \mathrm{Bi}_{10} \mathrm{Se}_{19}$. Indeed, both phases $\left(\mathrm{Sn}_{4.11} \mathrm{Bi}_{22.60} \mathrm{Se}_{38}\right.$ and $\left.\mathrm{Sn}_{4} \mathrm{Bi}_{10} \mathrm{Se}_{19}\right)$ share similar lattice parameters and feature mixed occupancy of $\mathrm{Sn}$ and $\mathrm{Bi}$ at all metal positions. However, while $\mathrm{Sn}_{4} \mathrm{Bi}_{10} \mathrm{Se}_{19}$ exhibits full occupancy of all metal positions, the $\mathrm{Sn}_{4.11} \mathrm{Bi}_{22.60} \mathrm{Se}_{38}$ structure contains partially occupied metal positions, ${ }^{49}$ which seemed to be necessary 


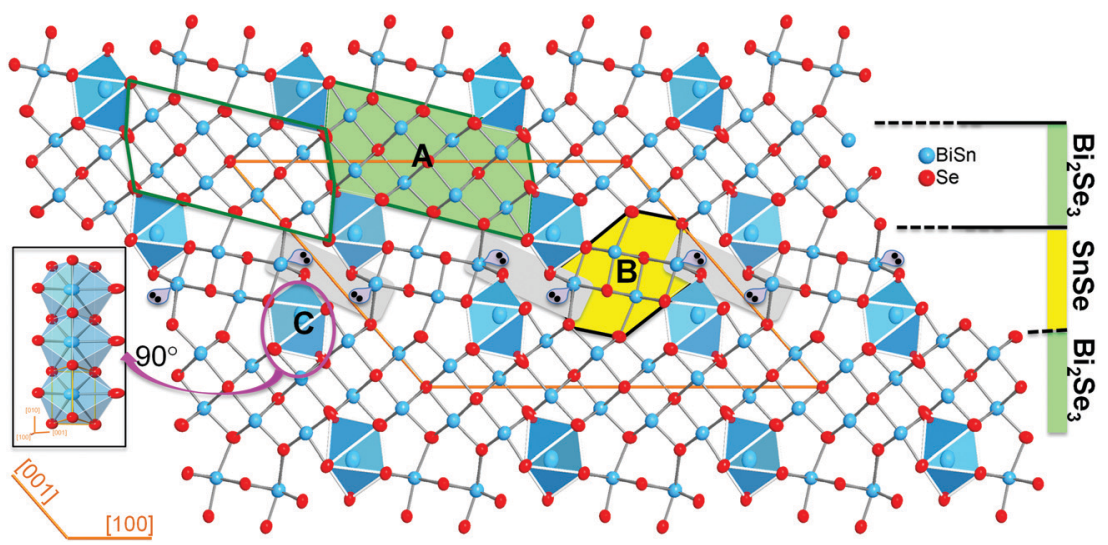

Fig. 1 Crystal structure of $\mathrm{Sn}_{4} \mathrm{Bi}_{10} \mathrm{Se}_{19}$ projected along [010] highlighting the major building blocks: a $\mathrm{Bi}_{2} \mathrm{Se}_{3}$-type block denoted $\mathrm{A}$; a SnSe-type block denoted $\mathrm{B}$ and a single chain of face-sharing bicapped trigonal prisms denoted $\mathrm{C}$. Adjacent $\mathrm{Bi}_{2} \mathrm{Se}_{3}$-type blocks are shifted by one row of metal atoms and share edges of $\left[\mathrm{MSe}_{6}\right.$ ] octahedra to form a $2 \mathrm{D} \mathrm{Bi}_{2} \mathrm{Se}_{3}$-layer parallel to the (001) plane. Adjacent $\mathrm{Bi}_{2} \mathrm{Se}_{3}$-layers stacked along [001] are interconnected by SnSe-type blocks to form a 3D crystal structure with open channels that are filled by the single chain of face-sharing [MSe $]_{8}$ bicapped trigonal prisms running along [010].

to maintain the electroneutrality of the compound..$^{45}$ Based on the final compositions of these two phases, we can establish the narrow solid-solution series of defect compounds with general formula $\mathrm{Bi}_{2 x} \mathrm{Sn}_{38-3 x} \mathrm{Se}_{38}$, where $10 \leq x<38 / 3$. The $\mathrm{Sn}_{4} \mathrm{Bi}_{10} \mathrm{Se}_{19}$ $(x=10)$ phase has the stoichiometric composition, whereas the $\mathrm{Sn}_{4.11} \mathrm{Bi}_{22.60} \mathrm{Se}_{38}(x=11.3)$ is a defect member containing $5 \%$ vacancies at various metal positions. ${ }^{49}$ Hypothetical compositions with high $x$ values, such as the $\mathrm{Sn}_{0.2} \mathrm{Bi}_{25.2} \mathrm{Se}_{38}(x \sim 12.6)$ phase, should display up to $\sim 10 \%$ vacancies at various metal positions in the crystal structure. Such flexibility in the $\mathrm{Sn} / \mathrm{Bi}$ ratio while maintaining the same crystal structure opens up more opportunities to tune the physical properties.

\section{Synthesis and thermal stability}

Despite the interesting crystal structure of the $\mathrm{Bi}_{2 x} \mathrm{Sn}_{38-3 x} \mathrm{Se}_{38}$ phases, where $10 \leq x<38 / 3$, and the prospect for the discovery of high-performance thermoelectric materials, difficulty in synthesizing highly crystalline single-phase samples suitable for measurement of electronic and thermal transport properties has hampered the ability to explore their thermoelectric properties. Achieving highly crystalline samples requires perfect stacking of the $2 \mathrm{D}$ $\mathrm{Bi}_{2} \mathrm{Se}_{3}$-layer and SnSe-layer into the 3D layered superlattice, which is extremely challenging owing to the complexity of the $\mathrm{Bi}_{2} \mathrm{Se}_{3}$-type and SnSe-type building blocks.

Therefore, we developed a multistep synthesis procedure for the fabrication of highly crystalline single-phase polycrystalline powder of $\mathrm{Sn}_{4} \mathrm{Bi}_{10} \mathrm{Se}_{19}$. The structurally disordered but elementhomogeneous sample 1 (S1) was initially obtained through solid-state reaction of high-purity elements sealed in an evacuated quartz tube followed by repeated melting and quenching of the product from solid-state reaction using an induction melting furnace. The XRD patterns of the resulting sample S1 showed very poor matching with the theoretical pattern calculated using single crystal structure data (Fig. 2). However, the DSC curves (Fig. S3, $\mathrm{ESI} \dagger$ ) showed a single broad endothermic peak of melting at around $940 \mathrm{~K}$ on heating and a single broad exothermic peak of crystallization with onset at $940 \mathrm{~K}$ on cooling. This suggests the formation of a disordered, poorly crystalline $\mathrm{Sn}_{4} \mathrm{Bi}_{10} \mathrm{Se}_{19}$ with congruent melting upon heating. Using the DSC heating and cooling data from sample S1, several annealing recipes were attempted to achieve highly crystalline samples. The best crystalline samples (S2) were obtained by heating the induction-melted product $\mathrm{S} 1$ to $973 \mathrm{~K}\left(50{ }^{\circ} \mathrm{C}\right.$ above the melting temperature) to achieve a thick molten state, followed by a slow cooling across the crystallization window ( $973 \mathrm{~K}$ to $927 \mathrm{~K}$ in 48 hours) in order to allow enough time for self-organization of the large building units. The sample was subsequently held at $927 \mathrm{~K}$, the lower limit of the crystallization window, for another 48 hours and finally cooled to room temperature in 12 hours. A comparison of the XRD pattern of the resulting sample with the theoretical pattern showed excellent matching (Fig. 2B), implying the formation of highly

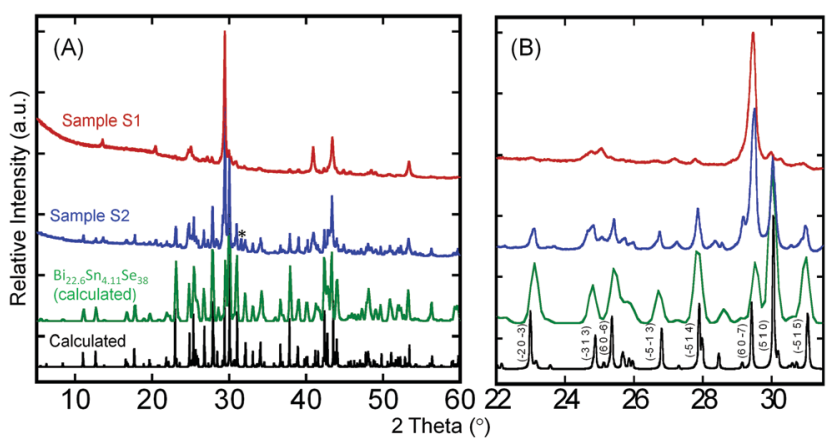

Fig. 2 X-Ray diffraction patterns of $\mathrm{Sn}_{4} \mathrm{Bi}_{10} \mathrm{Se}_{19}$ samples. (A) Comparison of the XRD patterns of the sample S1 obtained after SSR followed by the $I M Q$ process and the sample S2 obtained after the recrystallization process, with the theoretical patterns of $\mathrm{Sn}_{4} \mathrm{Bi}_{10} \mathrm{Se}_{19}$ and $\mathrm{Sn}_{4.11} \mathrm{Bi}_{22.6} \mathrm{Se}_{38}$ calculated using single crystal data; (B) enlarged section of the XRD patterns with indexed major diffraction peaks highlighting the excellent match, in peak position, between the XRD pattern of the S2 sample and the calculated patterns. Poorly resolved and missing peaks from the XRD pattern of the S1 sample suggests poor crystallinity. * denotes a peak from metallic Bi as a minor impurity phase. 
crystalline nearly single-phase samples of $\mathrm{Sn}_{4} \mathrm{Bi}_{10} \mathrm{Se}_{19}$. A rough analysis of the phase composition of $\mathrm{S} 2$ sample suggests that it consists essentially of $\mathrm{Sn}_{4} \mathrm{Bi}_{10} \mathrm{Se}_{19}(53 \%)$ and $\mathrm{Sn}_{4.11} \mathrm{Bi}_{22.60} \mathrm{Se}_{38}$ (42\%), which are both members of the solid solutions series $\mathrm{Bi}_{2 x} \mathrm{Sn}_{38-3 x} \mathrm{Se}_{38}$ discussed above, in addition to metallic Bi (5\%) as a minor impurity (Fig. S2, ESI $\dagger$ ). The observation of metallic $\mathrm{Bi}$ in the sample is consistent with the formation of the $\mathrm{Sn}_{4.11} \mathrm{Bi}_{22.60} \mathrm{Se}_{38}$ phase, which only seems to stabilize with $5 \%$ vacancy at all metal positions.

Interestingly, the S2 sample exhibits similar DSC curves with the disordered poorly crystalline sample S1 (Fig. S3B, ESI $\dagger$ ). However, careful analysis of the melting peaks for both S1 and S2 samples (Fig. S3E, ESI $\dagger$ ) revealed a single broad peak for poorly crystalline sample, $\mathrm{S} 1$, whereas the highly crystalline sample, S2, showed two clear peaks at $935 \mathrm{~K}$ and $945 \mathrm{~K}$. The peak at $935 \mathrm{~K}$ could be assigned to peritectic formation, whereas the liquidus appears at $945 \mathrm{~K}$. The striking similarity between the DSC curves of samples S1 and S2 despite their quite different XRD patterns indicates that all the chemical bonds and building blocks observed in the crystal structure of $\mathrm{Sn}_{4} \mathrm{Bi}_{10} \mathrm{Se}_{19}$ are already present in the poorly crystalline sample, $\mathrm{S} 1$, obtained through solid-state reaction followed by inductionmelting. However, due to the fast-cooling process, the building blocks did not fully order as anticipated from the single crystal structure, hence the formation of the poorly crystallized "amorphous" sample, S1. Upon reheating the sample S1 above the melting temperature and slowly cooling across the crystallization window, the building blocks became mobile again and the ordering process was activated in sample S2. The ability to synthesize both the poorly crystallized (S1) and wellcrystallized (S2) samples of $\mathrm{Sn}_{4} \mathrm{Bi}_{10} \mathrm{Se}_{19}$ enables a unique opportunity to investigate the effect of the evolution of atomic structure ordering on the electronic and thermal transport properties.

\section{Thermal conductivity}

Fig. 3 shows the thermal conductivities of both the S1 and S2 samples of $\mathrm{Sn}_{4} \mathrm{Bi}_{10} \mathrm{Se}_{19}$. It is interesting to note that the poorly crystallized sample (S1) displays a larger total and lattice thermal conductivity than the well-crystallized sample (S2). Nevertheless, both samples exhibit ultralow total thermal conductivity with room temperature values of $0.75 \mathrm{~W} \mathrm{~m}^{-1} \mathrm{~K}^{-1}$ and $0.70 \mathrm{~W} \mathrm{~m} \mathrm{~m}^{-1} \mathrm{~K}^{-1}$ for the $\mathrm{S} 1$ and $\mathrm{S} 2$ samples, respectively (Fig. 3A). The total thermal conductivity of both samples decreases with increasing temperature, reaching the minimum value of $0.70 \mathrm{~W} \mathrm{~m}^{-1} \mathrm{~K}^{-1}$ and $0.59 \mathrm{~W} \mathrm{~m}^{-1} \mathrm{~K}^{-1}$ at $510 \mathrm{~K}$ for the $\mathrm{S} 1$ and S2 samples, respectively. The difference is a $16 \%$ drop in the total thermal conductivity due to the increased ordering of structural building blocks within the polycrystalline sample. Further increasing the temperature leads to a gradual increase in the total thermal conductivity, which we attribute to bipolar conduction.

To understand the origin of the observed drop in the total thermal conductivity, lattice thermal conductivities $\left(\kappa_{\mathrm{L}}\right)$ were calculated by subtracting the electronic thermal conductivity $\left(\kappa_{\mathrm{e}}\right)$ from the total thermal conductivity $\left(\kappa_{\mathrm{L}}=\kappa_{\text {tot }}-\kappa_{\mathrm{e}}\right)$. The electronic
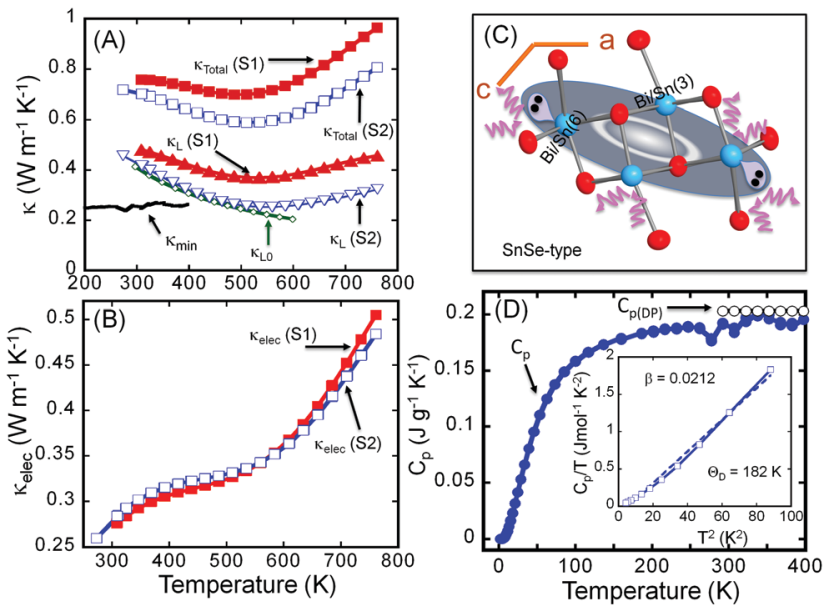

Fig. 3 Thermal conductivity and heat capacity of $\mathrm{Sn}_{4} \mathrm{Bi}_{10} \mathrm{Se}_{19}$. (A) Temperature dependence of the total $\left(\kappa_{\text {Total }}\right)$ and lattice $\left(\kappa_{\mathrm{L}}\right)$ thermal conductivity of the as-synthesized sample (S1) and the sample after recrystallization (S2) compared to the minimum thermal conductivity $\left(\kappa_{\min }\right)$ and the theoretical lattice thermal conductivity $\left(\kappa_{\mathrm{LO}}\right)$; (B) temperature-dependent electronic thermal conductivity $\left(\kappa_{\text {elec }}\right)$; (C) model of the rattling unit originating from the loneelectron-pair stereoactivity; (D) temperature-dependent heat capacity compared to the Dulong-Petit value.

thermal conductivity was calculated using the Wiedemann-Franz law, $\kappa_{\mathrm{e}}=L \sigma T$, where $L, \sigma$ and $T$ are the Lorenz constant, electrical conductivity and absolute temperature, respectively. Here, we adopt the Lorenz constant value, $L=2.45 \times 10^{-8} \mathrm{~W} \Omega \mathrm{K}^{-2}$ given the degenerate semiconducting behavior of the electrical conductivity, for the calculation of the electronic thermal conductivity.

Given the very similar electrical properties of S1 and S2 samples, their electronic thermal conductivities are quite identical regardless of the temperature (Fig. 3B). Therefore, the large difference observed in the total thermal conductivities of the S1 and S2 samples essentially comes from the lattice thermal conductivity (Fig. 3A) influenced by bonding inhomogeneity. The samples display room temperature lattice thermal conductivity values of $0.48 \mathrm{~W} \mathrm{~m}^{-1} \mathrm{~K}^{-1}$ and $0.42 \mathrm{~W} \mathrm{~m}^{-1} \mathrm{~K}^{-1}$ for $\mathrm{S} 1$ and $\mathrm{S} 2$, respectively. Upon increasing the temperature, the lattice thermal conductivities decrease to ultralow values of $0.37 \mathrm{~W} \mathrm{~m}^{-1} \mathrm{~K}^{-1}$ and $0.26 \mathrm{~W} \mathrm{~m}^{-1} \mathrm{~K}^{-1}$ at $510 \mathrm{~K}$ for the $\mathrm{S} 1$ and $\mathrm{S} 2$ samples, respectively, which is approximately a $30 \%$ reduction in the lattice thermal conductivity arising due to the improved crystallinity of the sample. Typically, amorphous materials are expected to display lower thermal conductivity than their highly crystalline counterpart due to increased phonon scattering from the high density of grain boundaries and interfaces arising from short range order, and random distribution or misorientation of structural building units in the polycrystalline sample. To understand the departure from this general trend in the "amorphous" $\mathrm{Sn}_{4} \mathrm{Bi}_{10} \mathrm{Se}_{19}$ sample, $\mathrm{S} 1$, we must first elucidate the origin of ultralow thermal conductivity in the highly crystalline $\mathrm{Sn}_{4} \mathrm{Bi}_{10} \mathrm{Se}_{19}$ sample, S2. Careful analysis of various coordination polyhedra formed by Se atoms around metal atoms as well as the distribution of the metalselenium (M-Se) distances within various building blocks in the $3 \mathrm{D}$ crystal structure suggests severe local structural distortions 
(Fig. S1 and Table S3, ESI $\dagger$ ). The observed distortion of the coordination polyhedra around $\mathrm{Bi}$ atoms in complex selenides typically implies stereochemical activity of the $5 \mathrm{~s}^{2}$ lone-electron-pair (LEP). Interestingly, within the 3D structure, the LEPs within the building SnSe-type unit B (Fig. 3C) agglomerate into micelles (highlighted by grey-shaded areas in Fig. 1) with the lobes pointing towards each other. The mutual repulsion between the lobes of the LEPs within individual micellar structure sets in a soft vibrational mode that likely contributes to phonon scattering at the atomic scale. In addition, the repulsion between LEPs induces strong distortion of $\mathrm{M}-\mathrm{Se}$ bond distances. This leads to strong bond anharmonicity and phonon scattering at the interfaces between various building blocks $(\mathrm{A}-\mathrm{C})$ within the crystal structure, which further support the observed ultralow thermal conductivity of the crystalline $\mathrm{Sn}_{4} \mathrm{Bi}_{10} \mathrm{Se}_{19}$ sample. Alternatively, the low lattice thermal conductivity of $\mathrm{Sn}_{4} \mathrm{Bi}_{10} \mathrm{Se}_{19}$ can be rationalized by taking into account bonding inhomogeneity and anisotropy within the crystal structure. Indeed, the presence of ordered building units $(\mathrm{A}-\mathrm{C})$ with dissimilar chemistries within the structure produces regions with different bonding, which hinder the phonon transport. ${ }^{28}$

The observed value of the lattice thermal conductivity of the highly crystalline $\mathrm{Sn}_{4} \mathrm{Bi}_{10} \mathrm{Se}_{19}$ sample, $0.42 \mathrm{~W} \mathrm{~m}^{-1} \mathrm{~K}^{-1}$ at $300 \mathrm{~K}$, was further validated by calculating the theoretical "intrinsic" lattice thermal conductivity $\left(\kappa_{\mathrm{LO}}\right)$, within the temperature range where only acoustic phonons conduct heat. The theoretical "intrinsic" lattice thermal conductivity $\left(\kappa_{\mathrm{L} 0}\right)$, was calculated (see ESI $\dagger$ ) using the Grüneisen parameter, $\gamma=1.86$, obtained from the sound velocity measurement and the Debye temperature, $\Theta=182 \mathrm{~K}$, obtained from the heat capacity measurement (Fig. 3D) and sound velocity measurement (Table S4, ESI $\dagger$ ). As shown in Fig. 3A, the calculated lattice thermal conductivity, $\kappa_{\mathrm{L} 0}=0.42 \mathrm{~W} \mathrm{~m}^{-1} \mathrm{~K}^{-1}$ at $300 \mathrm{~K}$ is consistent with the value of the lattice thermal conductivity extracted from the measured total thermal conductivity. In addition, $\kappa_{\mathrm{L} 0}$ at various temperatures follows very well, within the temperature range below $550 \mathrm{~K}, \kappa_{\mathrm{L}}$ extracted from experimental data.

To further benchmark the thermal conductivity of the crystalline $\mathrm{Sn}_{4} \mathrm{Bi}_{10} \mathrm{Se}_{19}$ sample, the "minimum thermal conductivity", $\kappa_{\text {min }}$, was calculated considering that the lattice thermal conductivity reaches the minimum value when the phonon meanfree-path (MFP) ( $l$ ) is equal to the average of the interatomic distances, using eqn (1).

$$
\kappa_{\min }=1 / 3\left(C_{\mathrm{v}} \nu_{\mathrm{m}} l\right)
$$

where $C_{\mathrm{v}}$ is the heat capacity at constant volume (in $\mathrm{J} \mathrm{m}^{-3} \mathrm{~K}^{-1}$ ) and $\nu_{\mathrm{m}}$ is the average sound velocity.

For $\mathrm{Sn}_{4} \mathrm{Bi}_{10} \mathrm{Se}_{19}$, the average interatomic distance is $l=3.06 \AA$, and the calculated value $\kappa_{\min }=0.26 \mathrm{~W} \mathrm{~m}^{-1} \mathrm{~K}^{-1}$ at $300 \mathrm{~K}$ (Fig. $3 \mathrm{~A}$ ) is very similar to the measured lattice thermal conductivity at $510 \mathrm{~K}$ for the $\mathrm{S} 2$ sample.

It follows from this analysis that the ultralow thermal conductivity observed in $\mathrm{Sn}_{4} \mathrm{Bi}_{10} \mathrm{Se}_{19}$ results from the combination of (1) local structure distortions due to the stereoactivity of LEPs, (2) inhomogeneity and anisotropy of chemical bonding, (3) the presence of heavy atoms in the crystal structure, (4) low crystal symmetry, and (5) the complexity of the layered 3D superlattice structure, which features a high density of interfaces between building blocks of very different sizes.

In light of the above analysis, we speculate that the rather larger total and lattice thermal conductivity measured from the poorly crystallized sample (S1) arises from the loss of the periodic superlattice arrangements of the $\mathrm{Bi}_{2} \mathrm{Se}_{3}$ - and $\mathrm{SnSe}$ - layers in favor of a more random orientation of various structural fragments formed by the three building blocks $\mathrm{A}$ ( $\mathrm{Bi}_{2} \mathrm{Se}_{3}$-type), B (SnSe-type) and $\mathrm{C}$ (chains of face-sharing bicapped trigonal prims around the M7 metal position) as illustrated in Fig. S4 (ESI $\dagger$ ). Within this picture, the bonding in the amorphous sample is more homogeneous and less anisotropic due to the building block disorder, which is more favorable to phonon transport. ${ }^{28}$

Our proposed structure of the poorly crystallized sample (S1) of $\mathrm{Sn}_{4} \mathrm{Bi}_{10} \mathrm{Se}_{19}$ is supported by both the DSC data and the XRD analysis (Fig. 2 and Fig. S3, ESI $\dagger$ ). The similarity in the DSC of S1 and S2 samples suggests that most of the structural building blocks and fragments formed by those building blocks are already present in the poorly crystallized structure. In addition, the presence of many sharp peaks on the XRD patterns of the S1 sample suggests some degrees of atomic ordering, while the poor matching of the diffraction peaks with the theoretical pattern from the single crystal structure analysis indicates lack of long-range order in the S1 sample. The poorly crystalline structure still maintains many of the local atomic-scale structural features that are believed to be responsible for the ultralow thermal conductivity of the well-crystallized sample (S2), which also justifies its ultralow thermal conductivity. However, the lack of (1) inhomogeneity and anisotropy of chemical bonding and (2) high density of interfaces, which would result from the long-range ordering of the building blocks into the observed 3D layered superlattice structure, results in weaker phonon scattering compared to the well-crystallized sample (S2). Consequently, the thermal conductivity of the poorly crystallized sample (S1) of $\mathrm{Sn}_{4} \mathrm{Bi}_{10} \mathrm{Se}_{19}$ is higher than that of the well-crystallized counterpart (S2).

\section{Electronic properties}

To probe the effect of structural ordering on the electronic properties, we have performed the temperature-dependent measurements of the electrical conductivity (Fig. 4A) and Hall effect (Fig. S5, ESI $\dagger$ ) on both the S1 and S2 samples in the temperature range from $2 \mathrm{~K}$ to $775 \mathrm{~K}$. These data were then used to calculate the variation of charge carrier concentration (n) (Fig. 4B) and charge carrier mobility ( $\mu$ ) (Fig. 4D) with the temperature in both samples. It can be noted that, while both samples exhibit very similar temperature dependence of the electronic properties $(n, \mu, \sigma)$ at temperatures above $300 \mathrm{~K}$, they display remarkably different electronic properties at low temperatures $(2 \mathrm{~K}$ to $300 \mathrm{~K})$. In general, the electrical conductivity of both samples gradually decreases with rising temperature in the temperature range from $2 \mathrm{~K}$ to $500 \mathrm{~K}$, indicating a degenerate semiconducting behavior. However, the rate at which the electrical conductivity drops depends on the temperature range. For instance, a rapid decrease in the electrical conductivity is observed between $2 \mathrm{~K}$ and $300 \mathrm{~K}$, which is associated with the 

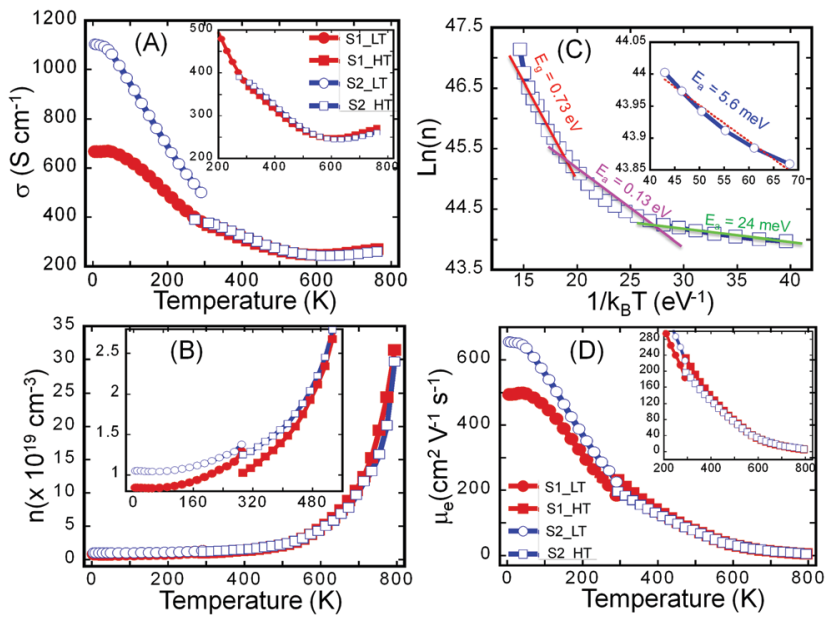

Fig. 4 Electronic transport of $\mathrm{Sn}_{4} \mathrm{Bi}_{10} \mathrm{Se}_{19}$. (A) Temperature-dependent electrical conductivity; (B) temperature-dependent charge carrier concentration; (C) fitting of the carrier concentration using the Arrhenius equation, highlighting the activation energy of impurities and the electronic band gap; (D) temperature-dependent charge carrier mobility.

sharp drop in the carrier mobility arising from the large increase in the carrier concentration. Indeed the fitting of the temperature-dependent carrier density curve using Arrhenius law $\left(\ln (n) \sim E_{\mathrm{a}} / k_{\mathrm{B}} T\right)$ suggests the presence, within the band gap $\left(E_{\mathrm{g}}=0.73 \mathrm{eV}\right)$, of several impurity states with activation energy, $E_{\mathrm{a}}$, ranging from $5.6 \mathrm{meV}$ to $130 \mathrm{meV}$ (Fig. 4C). At very low temperatures, a small increase in the temperature leads to the ionization of impurities located at $5.6 \mathrm{meV}$ below the conduction band (CB). Further increase in temperature leads to the ionization of impurities located in deeper states $(24 \mathrm{meV}$ and $130 \mathrm{meV})$. Such thermal activation of carriers from impurity states to the conduction band leads to the observed initial marginal increase in the carrier concentration between $2 \mathrm{~K}$ and $500 \mathrm{~K}$.

At temperatures above $500 \mathrm{~K}$, thermal excitation of electrons from the valence band (VB) to the conduction band ( $\mathrm{CB}$ ) leads to a drastic increase in the carrier concentration (Fig. 4B), which is also manifested by the transition of the temperaturedependent electrical conductivity from the heavy-doped semiconducting behavior to intrinsic semiconducting behavior. The above-described trend in the temperature-dependent electronic transport is valid for both the $\mathrm{S} 1$ and the $\mathrm{S} 2$ samples. The main difference in their electronic properties lies in the magnitude of the electrical conductivity, carrier density, and carrier mobility at various temperatures between $2 \mathrm{~K}$ and $300 \mathrm{~K}$. Within this temperature range, the $\mathrm{S} 2$ sample displays higher electronic properties (electrical conductivity, carrier concentration and carrier mobility) compared to the poorly crystalline sample (S1). For example, the electrical conductivity at $2 \mathrm{~K}$ is $\sim 1100 \mathrm{~S} \mathrm{~cm}^{-1}$ for the $\mathrm{S} 2$ sample compared to only $700 \mathrm{~S} \mathrm{~cm}^{-1}$ for the $\mathrm{S} 1$ sample. The carrier mobility at $2 \mathrm{~K}$ is $\sim 630 \mathrm{~cm}^{2} \mathrm{~V}^{-1} \mathrm{~s}^{-1}$ for the sample $\mathrm{S} 2$ and $500 \mathrm{~cm}^{2} \mathrm{~V}^{-1} \mathrm{~s}^{-1}$ for $\mathrm{S} 1$ while the carrier concentration at $2 \mathrm{~K}$ is $1.1 \times 10^{19} \mathrm{~cm}^{-3}$ for the sample S2 and $8.8 \times 10^{18} \mathrm{~cm}^{-3}$ for the sample S1. The relatively high carrier concentration in both samples is attributed to a doping effect from defects, such as anti-site defects originating from intermixing of $\mathrm{Sn}$ and $\mathrm{Bi}$ at various metal positions in the crystal structure or the presence of a small fraction of metallic Bi in the $\mathrm{S} 2$ sample.

The observed larger values of both the carrier concentration and carrier mobility in the sample S2 compared to S1 implies the presence of surface and interfaces defects in the amorphous samples that contribute to trapping and scattering of charge carriers. The density of those defects is significantly reduced during the recrystallization process leading to the fabrication of sample S2. Upon increasing the temperature, the carrier density in sample S2 increases marginally while the carrier density in sample $\mathrm{S} 1$ increases much more rapidly, likely due to the annealing of trapping defects. As a result, very similar carrier density and carrier mobility are achieved in both $\mathrm{S} 1$ and S2 samples at temperatures above $500 \mathrm{~K}$, where intrinsic carriers thermally excited from the valence band to the conduction band dominate the electrical conduction. The similarity of electrical properties for both S1 and S2 samples at high temperatures implies similar electronic structures of both materials, which is mainly determined by chemical bonding within the materials. This is consistent with the DSC result where only one melting peak and one crystallization peak were observed in heating and cooling process respectively for both materials. Evidently, all basic chemical bonds and sub building blocks of the $\mathrm{Sn}_{4} \mathrm{Bi}_{10} \mathrm{Se}_{19}$ structure are formed after induction melting. The subsequent annealing process completed for $\mathrm{S} 2$ reactivates the mobility of building blocks locked up at low temperature, to allow them to re-order in a crystalline fashion without breaking apart the chemical bonds.

Although the high temperature electronic properties of both S1 and S2 samples are very similar, low temperature Hall effect measurements (Fig. S5, ESI $\dagger$ ) can also probe their intrinsic electrical properties. The low temperature Hall effect data can be divided into two segments, including one below $50 \mathrm{~K}$ and the other one from 50 to $300 \mathrm{~K}$. The calculated carrier concentration plateaus below $50 \mathrm{~K}$ and thereafter starts to increase with rising temperature for both samples. Such a dual-segment Hall coefficient/carrier concentration indicates doping effects from two kinds of defects: one having shallow defect states and the other having deep defect states within the band gap, which is consistent with our analysis of the temperature dependent carrier concentration. The shallow defect states are excited at extremely low temperature, which was not observed in our Hall effect measurement, and set the initial carrier concentration. The deep defect states are excited at temperatures ranging from $50 \mathrm{~K}$ to $300 \mathrm{~K}$.

The combination of ultralow thermal conductivity and high charge carrier mobility in $\mathrm{Sn}_{4} \mathrm{Bi}_{10} \mathrm{Se}_{19}$ is a hallmark of a promising thermoelectric material. While the ultralow thermal conductivity is attributed to the combination of local structural distortions, the presence of multiple building blocks within the crystal structure, and the presence of a high density of interfaces between the building blocks in all three directions, the observed high charge carrier mobility of $\sim 250 \mathrm{~cm}^{2} \mathrm{~V}^{-1} \mathrm{~s}^{-1}$ at $300 \mathrm{~K}$ for both samples ( $\mathrm{S} 1$ and $\mathrm{S} 2$ ) can be attributed to the presence of the $2 \mathrm{D} \mathrm{Bi}_{2} \mathrm{Se}_{3}$-layer in the $3 \mathrm{D}$ crystal structure (Fig. 1), which ensures a high carrier mobility within the $a b$ plane. 

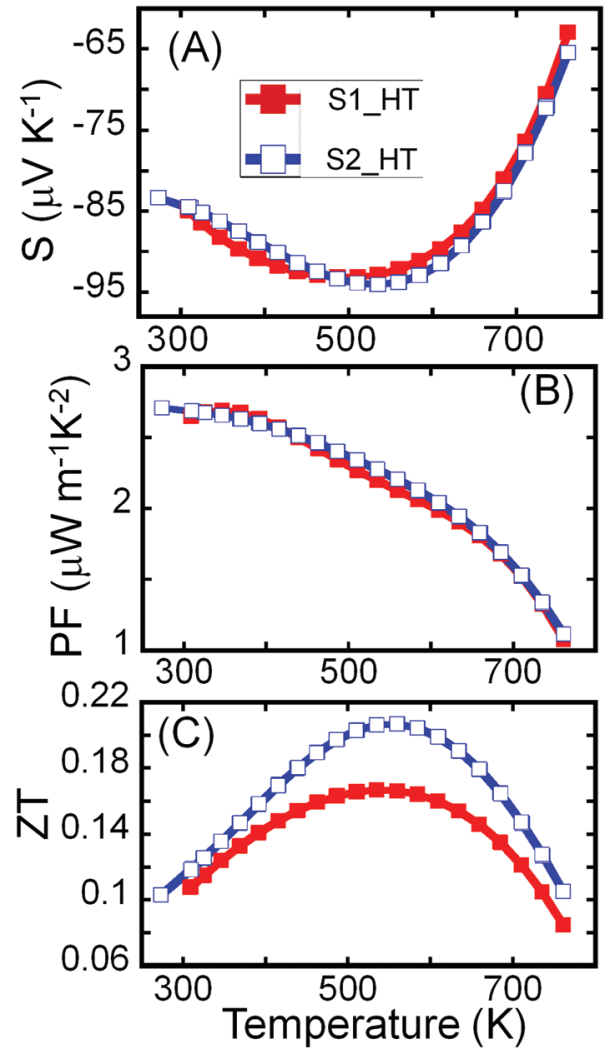

Fig. 5 Temperature-dependent thermoelectric properties of $\mathrm{Sn}_{4} \mathrm{Bi}_{10} \mathrm{Se}_{19}$ (A) Thermopower; (B) power factor; (C) figure of merit, $Z T$.

The observed carrier mobility of $\mathrm{Sn}_{4} \mathrm{Bi}_{10} \mathrm{Se}_{19}$ is higher than that of polycrystalline n-type $\operatorname{SnSe}\left(\sim 125 \mathrm{~cm}^{2} \mathrm{~V}^{-1} \mathrm{~s}^{-1}\right.$ at $300 \mathrm{~K})^{50}$ and comparable to that of polycrystalline n-type $\mathrm{Bi}_{2} \mathrm{Se}_{3}$ $\left(\sim 310 \mathrm{~cm}^{2} \mathrm{~V}^{-1} \mathrm{~s}^{-1} \text { at } 300 \mathrm{~K}\right)^{51}$ with similar carrier concentration ( $n \sim 10^{19} \mathrm{~cm}^{-3}$ ). Interestingly, the total thermal conductivity of polycrystalline $\mathrm{Sn}_{4} \mathrm{Bi}_{10} \mathrm{Se}_{19}\left(0.7 \mathrm{~W} \mathrm{~m}^{-1} \mathrm{~K}^{-1}\right.$ at $\left.300 \mathrm{~K}\right)$ is comparable to that of polycrystalline n-type SnSe $\left(\sim 0.9 \mathrm{~W} \mathrm{~m}^{-1} \mathrm{~K}^{-1} \text { at } 300 \mathrm{~K}\right)^{50}$ and is $100 \%$ lower than that of polycrystalline n-type $\mathrm{Bi}_{2} \mathrm{Se}_{3}$ $\left(1.4 \mathrm{~W} \mathrm{~m}^{-1} \mathrm{~K}^{-1}\right.$ at $\left.300 \mathrm{~K}\right) .^{52}$ Such structurally induced multifunctionalities, where the high carrier mobility of $\mathrm{Bi}_{2} \mathrm{Se}_{3}$ is combined with the low thermal conductivity of SnSe, make the $\mathrm{Sn}_{4} \mathrm{Bi}_{10} \mathrm{Se}_{19}$ phase and structurally related compounds, like $\mathrm{Cu}_{2} \mathrm{~Pb}_{6} \mathrm{Bi}_{8} \mathrm{~S}_{19}{ }^{47} \mathrm{~K}_{0.66} \mathrm{Sn}_{4.82} \mathrm{Bi}_{11.18} \mathrm{Se}_{22}{ }^{48}$ and $\mathrm{Sn}_{4.11} \mathrm{Bi}_{22.60} \mathrm{Se}_{38}{ }^{49}$ great examples of chemically synthesizable phonon-glass electron crystal (PGEC) superlattices suitable for thermoelectric energy conversion.

Both samples ( $\mathrm{S} 1$ and $\mathrm{S} 2$ ) of $\mathrm{Sn}_{4} \mathrm{Bi}_{10} \mathrm{Se}_{19}$ show n-type semiconducting behavior, as can be attested to by the negative values of the Hall effect (Fig. S5, ESI $\dagger$ ) and Seebeck coefficient (Fig. 5A). The Seebeck coefficients of these samples first increase linearly with increasing temperature, consistent with the heavily doped semiconducting behavior, reach a maximum at $500 \mathrm{~K}$ and then drop rapidly with further increase in temperature. The trend is consistent with the temperature dependence of the carrier density. The observed upturn at $500 \mathrm{~K}$ in both electrical conductivity and Seebeck coefficient imply bipolar conduction at higher temperature due to the thermal excitation of carriers across the narrow band gap $\left(E_{\mathrm{g}}=\right.$ $0.73 \mathrm{eV}$ ) that is typically reported for $\mathrm{Sn}-\mathrm{Bi}-\mathrm{Se}$ compounds. ${ }^{36,53,54}$

Due to the similarity in the electrical conductivity and Seebeck coefficient of both samples at high temperatures, comparable power factors $\left(S^{2} \sigma\right)$ were obtained (Fig. 5B). The power factor decreases with rising temperature with a maximum of $\sim 2.7 \mu \mathrm{W} \mathrm{m}{ }^{-1} \mathrm{~K}^{-2}$ observed at $300 \mathrm{~K}$. The continuous decrease in the power factor with increasing temperature results from the drop in the electrical conductivity near room temperature and the significant degradation of the Seebeck coefficient at temperatures above $500 \mathrm{~K}$. Given the much lower thermal conductivity, the largest figure of merit $Z T$ (Fig. 5C) was observed for the crystalline sample, S2. Due to the combination of decent electronic properties and low thermal conductivity, a peak $Z T$ above 0.2 was obtained at $535 \mathrm{~K}$ for the highly crystalline sample, $\mathrm{S} 2$, without optimization, making the $\mathrm{Sn}_{4} \mathrm{Bi}_{10} \mathrm{Se}_{19}$ compound another promising earth-abundant material for thermoelectric application at moderate temperatures.

\section{Conclusion}

We have successfully synthesized $\mathrm{Sn}_{4} \mathrm{Bi}_{10} \mathrm{Se}_{19}$ bulk samples in both poorly crystallized (S1) and well-crystallized (S2) forms using a combination of (1) solid-state reaction (SSR) of the elements at high temperature, (2) induction melting and quenching (IMQ) of the products from SSR, and (3) directional solidification starting from ingots obtained from the IMQ process. Careful investigation of the crystal structure using XRD on single crystals revealed that $\mathrm{Sn}_{4} \mathrm{Bi}_{10} \mathrm{Se}_{19}$ adopts a complex monoclinic structure consisting of a $\mathrm{Bi}_{2} \mathrm{Se}_{3}$-like layer and a SnSe-like layer parallel to the (001) plane that are stacked alternatively along [001] to form a complex synthetic - $/ \mathrm{Bi}_{2} \mathrm{Se}_{3} /$ $\mathrm{SnSe} / \mathrm{Bi}_{2} \mathrm{Se}_{3} /$ - superlattice structure. Interestingly, the complexity of the structural building units renders the crystallization process from the liquid phase extremely challenging. We found that a fast cooling from the molten phase results in the formation of a poorly crystallized sample (S1), whereas slow directional solidification through the crystallization temperature window yields a well-crystallized sample (S2). Electronic transport measurements revealed that while both S1 and S2 samples exhibit similar properties at temperatures above $300 \mathrm{~K}$, the well-crystallized sample S2 displays larger electrical conductivity, carrier density and carrier mobility than the S1 sample in the temperature range from $2 \mathrm{~K}$ to $300 \mathrm{~K}$, which is attributed to the decrease in the density of carrier trapping and scattering defects in the S2 sample. Interestingly, a significantly lower total and lattice thermal conductivity was observed for the S2 sample compared to the S1 sample. This is believed to originate from the decrease in (1) the inhomogeneity and anisotropy of chemical bonding and (2) the density of interfaces between building blocks in the $\mathrm{S} 1$ sample due to their poor arrangement. However, both the S1 and S2 samples showed ultralow thermal conductivity, which further support the similarity in their atomic structure. Remarkably, the $\mathrm{Sn}_{4} \mathrm{Bi}_{10} \mathrm{Se}_{19}$ samples (both S1 and S2) integrate the high-carrier mobility 
observed in $\mathrm{Bi}_{2} \mathrm{Se}_{3}$ crystals with the low thermal conductivity of SnSe, resulting in a unique synthetically accessible example of a phonon-glass-electron-crystal (PGEC) superlattice with promising thermoelectric properties. The combination of moderate electronic properties and low thermal conductivity leads to a figure merit, $Z T$, of $\sim 0.2$ at $535 \mathrm{~K}$ for the unoptimized highly crystalline sample. The result highlights the potential of the atomic-scale integration of two or more large building blocks from simple binary compounds, each with dissimilar functionalities (such as high electrical conductivity and ultralow thermal conductivity), into complex superlattices or hierarchical structures as a powerful design approach towards new high-performance multifunctional materials.

\section{Author contributions}

R. L. and A. O. synthesized the samples, carried out thermoelectric measurements, performed the structural characterization and cowrote the manuscript. Z. Y. and B. B. helped with sample synthesis, structural characterization, data analysis, and co-edited the manuscript. T. B. and C. U. carried out the electrical conductivity, Seebeck coefficient, and Hall effect measurements and co-edited the manuscript. J. F., X. S. and X. T. synthesized the samples, performed structural characterization, data analysis, and co-edited the manuscript. I. V. and Y. G. performed sample processing, measured thermoelectric properties and co-edited the manuscript. P. F. P. P. conceived the experiment, analyzed the results and co-wrote the manuscript.

\section{Conflicts of interest}

The authors declare no competing financial interest.

\section{Acknowledgements}

P. F. P. P. and C. U. acknowledge financial support from the Department of Energy, Office of Basic Energy Sciences under Award \#DE-SC0018941 for the investigation of low temperature and high temperature electronic and thermal transports. P. F. P. P. also thanks the Max-Planck-Institut für Chemische Physik fester Stoffe for financial assistance during the sabbatical stay from June to August 2018.

\section{References}

1 A. J. Minnich, M. S. Dresselhaus, Z. F. Ren and G. Chen, Energy Environ. Sci., 2009, 2, 466.

2 A. S. Glen, CRC Handbook of Thermoelectrics, CRC Press, 1995, DOI: 10.1201/9781420049718.ch34.

3 J. P. Heremans, V. Jovovic, E. S. Toberer, A. Saramat, K. Kurosaki, A. Charoenphakdee, S. Yamanaka and G. J. Snyder, Science, 2008, 321, 554-557.

4 J. P. A. Makongo, D. K. Misra, X. Y. Zhou, A. Pant, M. R. Shabetai, X. L. Su, C. Uher, K. L. Stokes and P. F. P. Poudeu, J. Am. Chem. Soc., 2011, 133, 18843-18852.
5 Y. F. Liu, P. Sahoo, J. P. A. Makongo, X. Y. Zhou, S. J. Kim, H. Chi, C. Uher, X. Q. Pan and P. F. P. Poudeu, J. Am. Chem. Soc., 2013, 135, 7486-7495.

6 P. Sahoo, Y. F. Liu, J. P. A. Makongo, X. L. Su, S. J. Kim, N. Takas, H. Chi, C. Uher, X. Q. Pan and P. F. P. Poudeu, Nanoscale, 2013, 5, 9419-9427.

7 M. S. Dresselhaus, G. Chen, M. Y. Tang, R. G. Yang, H. Lee, D. Z. Wang, Z. F. Ren, J. P. Fleurial and P. Gogna, Adv. Mater., 2007, 19, 1043-1053.

8 K. Biswas, J. Q. He, I. D. Blum, C. I. Wu, T. P. Hogan, D. N. Seidman, V. P. Dravid and M. G. Kanatzidis, Nature, 2012, 489, 414-418.

9 P. F. P. Poudeu, J. D’Angelo, A. D. Downey, J. L. Short, T. P. Hogan and M. G. Kanatzidis, Angew. Chem., Int. Ed., 2006, 45, 3835-3839.

10 J. R. Sootsman, D. Y. Chung and M. G. Kanatzidis, Angew. Chem., Int. Ed., 2009, 48, 8616-8639.

11 G. J. Snyder and E. S. Toberer, Nat. Mater., 2008, 7, 105-114. 12 P. F. P. Poudeu, R. Lu, Y. F. Liu, P. Sahoo and A. Page, in Materials Aspect of Thermoelectricity, ed. C. Uher, CRC Press, Taylor and Francis Group, 2016, ch. 7, in print.

13 M. N. Leuenberger and D. Loss, Nature, 2001, 410, 789-793. 14 M. Mannini, F. Pineider, P. Sainctavit, C. Danieli, E. Otero, C. Sciancalepore, A. M. Talarico, M. A. Arrio, A. Cornia, D. Gatteschi and R. Sessoli, Nat. Mater., 2009, 8, 194-197.

15 L. Dawahre, R. Lu, H. Djieutedjeu, J. Lopez, T. Bailey, B. Buchanan, Z. Yin, C. Uher and P. Poudeu, ACS Appl. Mater. Interfaces, 2020, 12, 44991-44997.

16 H. L. Liu, X. Shi, F. F. Xu, L. L. Zhang, W. Q. Zhang, L. D. Chen, Q. Li, C. Uher, T. Day and G. J. Snyder, Nat. Mater., 2012, 11, 422-425.

17 L. D. Zhao, S. H. Lo, Y. S. Zhang, H. Sun, G. J. Tan, C. Uher, C. Wolverton, V. P. Dravid and M. G. Kanatzidis, Nature, 2014, 508, 373-377.

18 L. D. Zhao, G. J. Tan, S. Q. Hao, J. Q. He, Y. L. Pei, H. Chi, H. Wang, S. K. Gong, H. B. Xu, V. P. Dravid, C. Uher, G. J. Snyder, C. Wolverton and M. G. Kanatzidis, Science, 2016, 351, 141-144.

19 L. L. Zhao, X. L. Wang, J. Y. Wang, Z. X. Cheng, S. X. Dou, J. Wang and L. Q. Liu, Sci. Rep., 2015, 5, 7671.

20 D. Li, X. Y. Qin, Y. F. Liu, C. J. Song, L. Wang, J. Zhang, H. X. Xin, G. L. Guo, T. H. Zou, G. L. Sun, B. J. Ren and X. G. Zhu, RSC Adv., 2014, 4, 8638.

21 L. Yang, Z. G. Chen, G. Han, M. Hong, Y. C. Zou and J. Zou, Nano Energy, 2015, 16, 367-374.

22 R. M. Lu, A. Olvera, T. P. Bailey, C. Uher and P. F. P. Poudeu, ACS Appl. Mater. Interfaces, 2020, 12, 31601-31611.

23 R. Lu, T. Bailey, C. Uher and P. Poudeu, ACS Appl. Energy Mater., 2020, 3, 9133-9142.

24 A. A. Olvera, N. A. Moroz, P. Sahoo, P. Ren, T. P. Bailey, A. A. Page, C. Uher and P. F. P. Poudeu, Energy Environ. Sci., 2017, 10, 1668-1676.

25 D. Y. Chung, T. Hogan, P. Brazis, M. Rocci-Lane, C. Kannewurf, M. Bastea, C. Uher and M. G. Kanatzidis, Science, 2000, 287, 1024-1027.

26 B. Poudel, Q. Hao, Y. Ma, Y. C. Lan, A. Minnich, B. Yu, X. A. Yan, D. Z. Wang, A. Muto, D. Vashaee, X. Y. Chen, 
J. M. Liu, M. S. Dresselhaus, G. Chen and Z. F. Ren, Science, 2008, 320, 634-638.

27 Y. S. Hor, A. Richardella, P. Roushan, Y. Xia, J. G. Checkelsky, A. Yazdani, M. Z. Hasan, N. P. Ong and R. J. Cava, Phys. Rev. B: Condens. Matter Mater. Phys., 2009, 79, 195208.

28 Y. Grin, J. Solid State Chem., 2019, 274, 329-336.

29 A. Mrotzek, L. Iordanidis and M. G. Kanatzidis, Inorg. Chem., 2001, 40, 6204-6211.

30 H. Ohta, W. S. Seo and K. Koumoto, J. Am. Ceram. Soc., 1996, 79, 2193-2196.

31 M. Ruck and P. F. P. Poudeu, Z. Anorg. Allg. Chem., 2008, 634, 482-490.

32 M. G. Kanatzidis, Acc. Chem. Res., 2005, 38, 359-368.

33 A. Mrotzek and M. G. Kanatzidis, Acc. Chem. Res., 2003, 36, 111-119.

34 B. Makovicky, W. C. Mumme and J. A. Watts, Can. Mineral., 1977, 15, 339-348.

35 A. Pring, M. Jercher and E. Makovicky, Mineral. Mag., 1999, 63, 917-926.

36 A. Olvera, G. S. Shi, H. Djieutedjeu, A. Page, C. Uher, E. Kioupakis and P. F. P. Poudeu, Inorg. Chem., 2015, 54, 746-755.

37 L. Shelimova, O. Karpinskii, P. Konstantinov, E. Avilov, M. Kretova, G. Lubman, I. Y. Nikhezina and V. Zemskov, Inorg. Mater., 2010, 46, 120-126.

38 L. Shelimova, O. Karpinskii and V. Zemskov, Inorg. Mater., 2008, 44, 927-931.

39 L. Shelimova, V. Zemskov, E. Avilov, M. Kretova, I. Y. Nikhezina and A. Mikhailova, Inorg. Mater., 2015, 6, 298-304.

40 V. Zemskov, L. Shelimova, P. Konstantinov, E. Avilov, M. Kretova and I. Nikhezina, Inorg. Mater., 2011, 2, 405-413.
41 Y. Zhang, A. P. Wilkinson, P. L. Lee, S. D. Shastri, D. Shu, D.-Y. Chung and M. G. Kanatzidis, J. Appl. Crystallogr., 2005, 38, 433-441.

42 M. Ohta, D. Y. Chung, M. Kunii and M. G. Kanatzidis, J. Mater. Chem. A, 2014, 2, 20048-20058.

43 J. Casamento, J. S. Lopez, N. A. Moroz, A. Olvera, H. Djieutedjeu, A. Page, C. Uher and P. F. P. Poudeu, Inorg. Chem., 2017, 56, 261-268.

44 K. Adouby, M. L. E. Moubtassim, C. P. Vicente, J. C. Jumas and A. A. Toure, J. Alloys Compd., 2008, 453, 161-166.

45 F. Heinke, P. Urban, A. Werwein, C. Fraunhofer, T. Rosenthal, S. Schwarzmüller, D. Souchay, F. Fahrnbauer, V. Dyadkin and G. Wagner, Inorg. Chem., 2018, 57, 4427-4440.

46 K.-B. Chen and C.-S. Lee, J. Solid State Chem., 2010, 183, 807-813. 47 D. Topa, E. Makovicky, T. C. Balić-Žunić and P. Berlepsch, Eur. J. Mineral., 2000, 12, 825-833.

48 A. Mrotzek, D.-Y. Chung, T. Hogan and M. G. Kanatzidis, J. Mater. Chem., 2000, 10, 1667-1672.

49 F. Heinke, A. Werwein and O. Oeckler, J. Alloys Compd., 2017, 701, 581-586.

50 C. Chang, M. Wu, D. He, Y. Pei, C.-F. Wu, X. Wu, H. Yu, F. Zhu, K. Wang and Y. Chen, Science, 2018, 360, 778-783.

51 R. Liu, X. Tan, G. Ren, Y. Liu, Z. Zhou, C. Liu, Y. Lin and C. Nan, Crystals, 2017, 7, 257.

52 G. Sun, X. Qin, D. Li, J. Zhang, B. Ren, T. Zou, H. Xin, S. B. Paschen and X. Yan, J. Alloys Compd., 2015, 639, 9-14. 53 K.-S. Choi, D.-Y. Chung, A. Mrotzek, P. Brazis, C. R. Kannewurf, C. Uher, W. Chen, T. Hogan and M. G. Kanatzidis, Chem. Mater., 2001, 13, 756-764.

54 A. A. Kozma, M. Y. Sabov, E. Y. Peresh, I. E. Barchiy and V. V. Tsygyka, Inorg. Mater., 2015, 51, 93-97. 